\title{
Typical Features of Amelogenesis Imperfecta in Two Patients with Bartter's Syndrome
}

\author{
Hercílio Martelli-Júnior ${ }^{a} \quad$ Shirlene Pimentel Ferreira ${ }^{b}$ \\ Paula Cristina B. Pereira ${ }^{c}$ Ricardo D. Coletta ${ }^{d}$ \\ Sibele Nascimento de Aquino ${ }^{d}$ Débora Marques Miranda ${ }^{c}$ \\ Ana Cristina Simões e Silva ${ }^{c}$ \\ a Stomatology Clinic, Dental School, State University of Montes Claros, Montes Claros, \\ ${ }^{b}$ Dental School, Federal University of Minas Gerais, and 'Pediatric Nephrology Unit, \\ Department of Pediatrics, INCT de Medicina Molecular, Faculty of Medicine, \\ Federal University of Minas Gerais, Belo Horizonte, dDepartment of Oral Diagnosis, \\ School of Dentistry, State University of Campinas, Piracicaba, Brazil
}

\section{Key Words}

Bartter's syndrome $\cdot$ Genetics $\cdot$ Amelogenesis imperfecta $\cdot$ Enamel

\begin{abstract}
Background/Aims: Amelogenesis imperfecta (Al) is due to many inherited defects of enamel formation that affect the quantity and quality of enamel, leading to delay in tooth eruption and cosmetic consequences. Al has been described in association with nephrocalcinosis, which is called the enamel-renal syndrome. The aim of this case report is to describe typical features of Al in 2 patients with Bartter's syndrome (BS) for the first time. Methods: -Eight patients with confirmed BS were systematically screened for dental abnormalities as part of protocol. Those with suggestive clinical features of Al were submitted to panoramic X-ray and decayed teeth were analyzed by scanning electron microscopy. Results: Typical features of Al were detected in 2 girls with BS. These 2 patients showed nephrocalcinosis, and diagnosis and adequate clinical control were delayed. Genetic analysis detected the mutation responsible for BS in 1 of these patients. In this case, BS was due to a homozygous mutation of exon 5 of the KCNJ1 gene resulting in a substitution of valine for alanine at the codon 214 (A214V). Conclusions: The finding of typical features of Al in BS might constitute preliminary evidence that abnormalities of the biomineralization process found in patients with renal tubular disorders might also affect calcium deposition in dental tissues.




\section{Introduction}

Bartter's syndrome (BS) is a rare and heterogeneous group of tubulopathies with recessive and dominant autosomal inheritance, due to impairment of sodium and chloride resorption in the thick ascending limb of Henle's loop [1]. These tubular alterations frequently lead to polyuria, polydipsia, failure to thrive, water and electrolyte imbalance, and nephrocalcinosis [2,3]. In Brazil, the diagnosis of BS is frequently late and, for this reason, patients are inadequately managed [4]. Therefore, the Pediatric Nephrology Unit at Federal University of Minas Gerais has a specialized outpatient clinic to diagnose and follow up patients with renal tubular disorders. A multidisciplinary team including pediatric nephrologists, nutritionists, psychologists and dentists evaluates all patients with confirmed tubulopathies.

The dental evaluation of our BS patients detected 2 cases with typical features of amelogenesis imperfecta (AI). AI is usually the result of many inherited defects of enamel formation that impair quantity and quality of enamel [5]. It might affect all or some teeth in the deciduous and/or permanent dentition. AI has been reported as an isolated or syndromic finding with an autosomal dominant, autosomal recessive or X-linked inheritance [6]. Many genes have been associated with isolated AI, such as genes of amelogenin, enamelin, enamelysin, KLK4, WDR72, FAM83H and FAM20 [6-8]. AI as part of a syndrome was already identified in cases of amelo-onycho-hypohidrotic syndrome, Kohlschutter syndrome, oculo-dento-osseous dysplasia, and epidermolysis bullosa hereditaria, among others $[9,10]$. The rare syndrome associating AI and nephrocalcinosis, also called enamelrenal syndrome, was first reported by MacGibbon in 1972 and, since then, another 10 reports in the literature were found [9]. Nephrocalcinosis is the result of calcium salts precipitation in renal tissue, found in cases with hypercalcemia and/or hypercalciuria such as renal tubular acidosis, BS, medullary sponge kidney, and hyperoxaluria [4]. No previous study reported the occurrence of defects in enamel formation in patients with BS. Therefore, the purpose of this study was to report 2 unrelated cases of BS showing typical features of AI.

\section{Methods and Case Reports}

Eight patients with confirmed BS were diagnosed between 1996 and 2010 and followed up at the Pediatric Nephrology Unity at Federal University of Minas Gerais, Brazil. All patients were submitted to a systematic protocol including clinical and nutritional evaluation, laboratory measurements, renal ultrasonography, genetic analysis, and oral examination. From patients' records, we collected the following data: age, gender, information on perinatal period (such as polyhydramnios, prematurity, and low birth weight), and presence of nephrocalcinosis. Parental consanguinity and/or a history of similar cases in the family were also verified. Informed consent was obtained from the parents or the legal guardians of the children, and this study was approved by the local ethics committee.

\section{Results}

Among 8 patients with BS, 4 were females and the mean age at diagnosis was 5 years and 7 months (ranging from 2 months to 10 years). There was no history of exposure to known teratogenic agents nor was there a history of maternal diseases. Nephrocalcinosis was found in 6 patients by renal ultrasonography $(75 \%)$ and polyhydramnios was reported in 5 patients 
Table 1. The main clinical findings of 8 patients with BS

\begin{tabular}{lllllllll}
\hline Clinical findings & Patient 1 & Patient 2* & Patient 3 & Patient 4 & Patient 5 & Patient 6 & Patient 7 & Patient 8 \\
\hline Age, years & 10 & 5 & 11 & 16 & 7 & 4 & 15 & 9 \\
Dentition & mixed & mixed & permanent & permanent & mixed & deciduous & permanent mixed \\
AI & + & - & - & - & + & - & - & - \\
Nephrocalcinosis & + & + & - & + & + & + & + & - \\
Parents' consanguinity & + & + & - & + & unknown & - & + & - \\
Polyhydramnios & + & + & - & + & unknown & + & + & - \\
Gender & female & female & male & male & female & male & male & female \\
\hline
\end{tabular}

$+=$ Presence; $-=$ absence. ${ }^{*}$ Sister of patient $1[9]$.

(62.5\%; table 1). Typical features of AI were found in 2 females (25\%) with a mixed dentition and associated nephrocalcinosis. The following is a brief clinical description of these 2 BS patients focusing on defects in enamel formation.

\section{Patient 1}

Because of the index case (patient 2) and the consanguinity of the parents, we considered the possibility of BS in the girl's older sister. She was born prematurely, after a polyhydramnios-complicated 34-week gestation, with low birth weight $(2,235 \mathrm{~g})$. During the first years of life, there were few symptoms. At the age of 3 years, she developed moderate polyuria and polydipsia, with mild failure to thrive. Laboratory work-up revealed hypochloremia $\left(\mathrm{Cl}^{-}=96 \mathrm{mmol} / \mathrm{l}\right)$, metabolic alkalosis $\left(\mathrm{HCO}^{-}=28 \mathrm{mEq} / \mathrm{l}\right)$ with low normal serum potassium levels, urinary salt loss (fractional excretion of $\mathrm{Na}^{+}=2 \%$ ), hyperfiltration (GFR of $\left.150 \mathrm{ml} / \mathrm{min} / 1.73 \mathrm{~m}^{2}\right)$, and high-to-normal urinary calcium levels $(3.8 \mathrm{mg} / \mathrm{kg} /$ day). The plasma renin activity $(2.2 \mathrm{ng} \mathrm{Ang} \mathrm{I/ml/h)} \mathrm{and} \mathrm{aldosterone}(47 \mathrm{pg} / \mathrm{ml})$ were increased. Renal ultrasound showed mild medullary nephrocalcinosis. As previously reported by our group, the genetic evaluation of this child confirmed the diagnosis of BS due to a homozygous mutation of the exon 5 of the KCNJ1 gene resulting in a substitution of valine for alanine at the codon $214(\mathrm{~A} 214 \mathrm{~V})$ of the two strands of the child and a heterozygous mutation in the parents [11].

Oral cavity examination revealed yellowish teeth presenting rough surfaces, and conspicuous and irregular defects (fig. 1a). The enamel alterations were generalized, affecting teeth in both arches. The gingiva was normal, without signs of inflammation. The radiographic examination showed mixed teeth (fig. 1b). In various teeth, no differences in density between enamel and dentin were observed. Teeth were extracted because of the decay and examined by scanning electron microscopy (SEM). SEM examination revealed a thin enamel layer with normal structure, alternated by rough areas with severe porosity and irregularly shaped empty spaces, which pointed to the diagnosis of thin hypoplastic AI (fig. 1c).

\section{Patient 5}

This girl was adopted at the age of 2 years. For this reason, we have no data on the perinatal period. Since the age of 3 years, the adoptive mother reported moderate polyuria and polydipsia, with failure to thrive. No laboratory investigations were performed until the age of 7 years when the girl exhibited a convulsion due to water and electrolyte disturbances. Laboratory work-up revealed hypochloremia $\left(\mathrm{Cl}^{-}=91 \mathrm{mmol} / \mathrm{l}\right)$, hyponatremia $\left(\mathrm{Na}^{+}=132\right.$ $\mathrm{mmol} / \mathrm{l})$, metabolic alkalosis $\left(\mathrm{HCO}_{3}{ }^{-}=28 \mathrm{mEq} / \mathrm{l}\right)$, severe hypokalemia $\left(\mathrm{K}^{+}=1.7 \mathrm{mmol} / \mathrm{l}\right)$, 

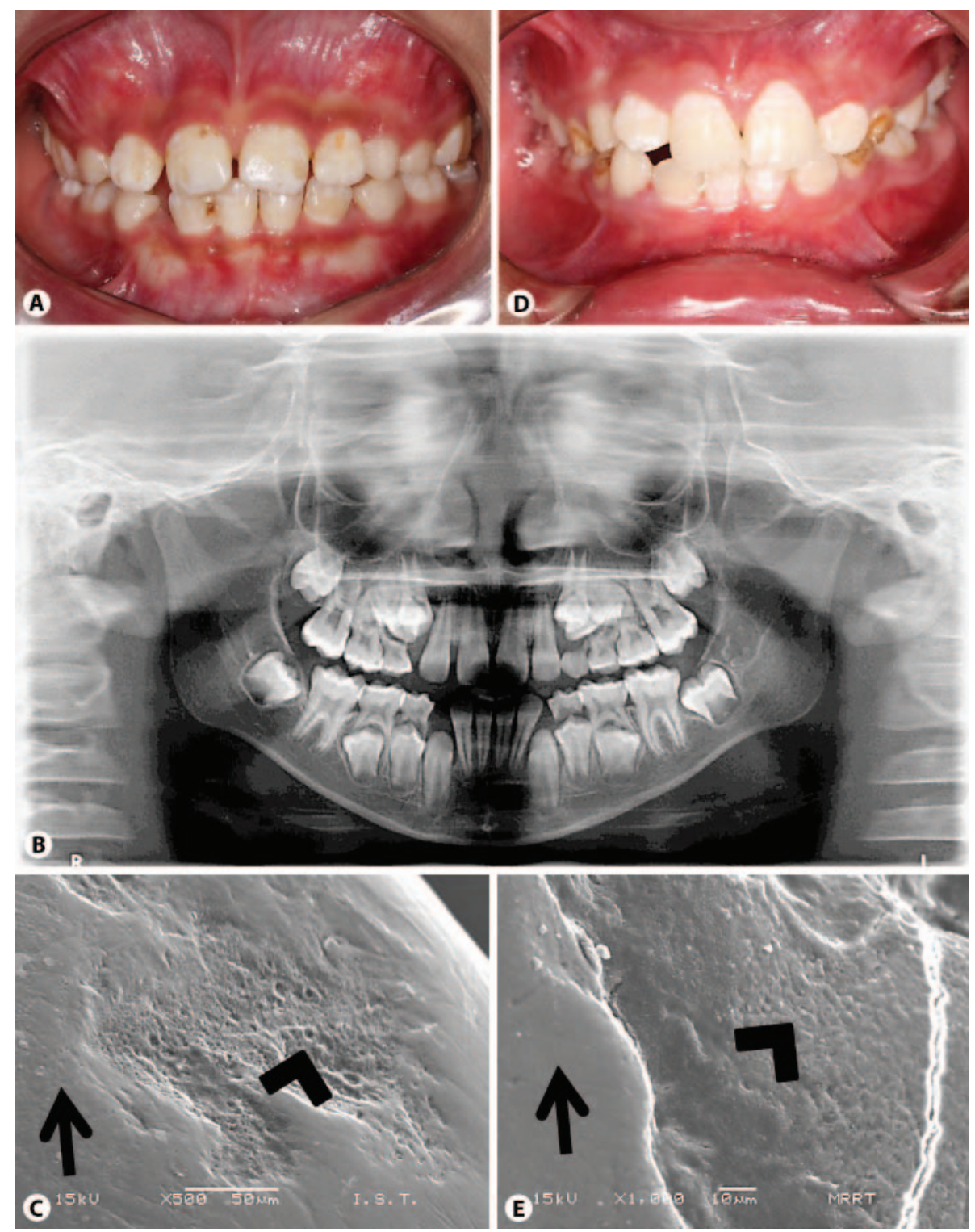

Fig. 1. A Intraoral examination of patient 1 revealed yellowish teeth presenting rough surfaces, and conspicuous and irregular defects. The enamel alterations were generalized, affecting teeth in both arches. The gingiva was normal. B Panoramic radiographs showing mixed teeth. In some teeth, lack of contrast between enamel and dentin is noted. C SEM micrograph of a tooth affected by AI. Enamel ultrastructure revealed a thin irregular enamel layer with normal structure (arrow) alternated by rough areas with severe porosity and irregularly shaped empty spaces (arrowhead). D Intraoral examination of patient 5 revealed yellowish teeth presenting rough surfaces, and conspicuous and irregular defects. The gingiva was normal. E SEM micrograph of a tooth affected by AI. Enamel ultrastructure revealed a thin irregular enamel layer with normal structure (arrow) alternated by rough areas with severe porosity and irregularly shaped empty spaces (arrowhead). 
urinary salt loss (fractional excretion of $\mathrm{Na}^{+}=2.8 \%$ ), hyperfiltration (GFR of $220 \mathrm{ml} / \mathrm{min}$ / $\left.1.73 \mathrm{~m}^{2}\right)$, and slight elevation of urinary calcium levels $(4.6 \mathrm{mg} / \mathrm{kg} /$ day $)$. The plasma renin activity (10.8 $\mathrm{ng} \mathrm{Ang} \mathrm{I/ml/h)} \mathrm{and} \mathrm{aldosterone}(38 \mathrm{pg} / \mathrm{ml})$ were increased. Renal ultrasound showed mild medullary nephrocalcinosis.

The intraoral examination detected almost the same findings as in patient 1 . Intraoral examination revealed yellowish teeth presenting rough surfaces, and conspicuous and irregular defects (fig. 1d). The radiographic examination showed mixed teeth. In various teeth, density of enamel and dentin was normal. Teeth were also extracted because of the decay and examined by SEM, which revealed a thin enamel layer with normal structure, alternated by rough areas with severe porosity and irregularly shaped empty spaces, which pointed to the diagnosis of thin hypoplastic AI (fig. 1e).

\section{Discussion}

There are very few reports of dental alterations in patients with renal tubular disorders [12]. However, we hypothesized that alterations in mineral metabolism commonly found in renal tubular disorders might be associated with dental abnormalities. Dental enamel is the most mineralized tissue in the human body. Mature enamel contains $>95 \%$ mineral content, while its organic content is $<1 \%$ [13]. The initial secretion of the dentin matrix by odontoblasts is followed by the secretion of the enamel matrix by ameloblasts [14]. The enamel matrix is subsequently calcified and matured across the removal of remaining enamel matrix proteins and by the growth of the enamel crystallites. Alterations in any of these steps induce development of enamel defects [14] and some children do not show tooth eruption. Enamel malformation might result in dental enamel defects such as discoloration of teeth, thin and/ or smooth tooth enamel, and easily damaged teeth, among others $[5,14]$. The enamel alterations observed by the oral and electron microscopic examinations of the 2 girls with BS were compatible with hypoplastic AI. Since AI might involve social and psychological consequences such as poor oral hygiene, lower self-esteem, and impaired quality of life [15], early identification and treatment is important in order to avoid aesthetical and functional consequences of AI.

Genetic evaluation definitely confirmed the diagnosis of BS in patient 1 [11] and allows us to infer that typical AI features might occur in BS. BS in patient 1 was caused by a mutation at KCNJ1 gene. So far, nephrocalcinosis in SB might be present in individuals with mutations of the KCNJ1 and SLC12A1 genes [16]. As a result of the mutation at KCNJ1 gene, the calcification process is probably altered in our patient 1 , leading to hypercalciuria and nephrocalcinosis. Since nephrocalcinosis is a common feature of BS [17] and the association between AI and nephrocalcinosis is also already established [9], we might speculate that AI features are related with nephrocalcinosis and altered biomineralization of the enamel. Both our patients diagnosed with AI had nephrocalcinosis and a long period of uncontrolled disorder, probably related to the severity of the disorder and/or length of time without adequate treatment. However, AI was not identified in the remaining 6 patients with BS, despite the presence of nephrocalcinosis in 4 of them. Since the development of nephrocalcinosis will depend upon tubular delivery of calcium to the interstitium, as well as prevailing local conditions, including $\mathrm{pH}$, inhibitory proteins, and anion concentrations [18], the connection between BS and typical features of AI is far more complex than only being a direct result of nephrocalcinosis and/or hypercalciuria. Therefore, studies about the molecular mechanisms of calcium transport in renal tubules and dental tissues are obviously necessary to understand the pathways and/or alterations in calcium homeostasis that might link BS and defects in enamel formation. 
In conclusion, we report the first 2 cases of typical AI features in patients with BS. Our patients with confirmed tubulopathies were routinely submitted to oral examination and the finding of AI features in 2 cases of BS suggests that dental alterations should be at least evaluated in these patients, especially in the presence of mutations at the KCNJ1 or SLC12A1 genes. Our findings might constitute preliminary evidence that abnormalities of the biomineralization process in patients with renal tubular disorders might also affect calcium deposition in dental tissues.

\section{Acknowledgments}

This work was supported by grants from the Fundação de Amparo a Pesquisa do Estado de Minas Gerais-FAPEMIG, Belo Horizonte, Brazil (to H.M.-J.) and the Conselho Nacional de Desenvolvimento Científico e Tecnologico-CNPq, Brazil (to H.M.-J., R.D.C., and A.C.S.S.). A.C.S.S. and D.M.M. also received a grant from Instituto Nacional de Ciência e Tecnologia de Medicina Molecular (FAPEMIG: CBB-APQ-00075-09/CNPq 573646/2008-2).

\section{References}

1 Brochard K, Boyer O, Blanchard A, Loirat C, Niaudet P, Macher MA, Deschenes G, Bensman A, Decramer S, Cochat P, Morin D, Broux F, Caillez M, Guyot C, Novo R, Jeunemaître X, Vargas-Poussou R: Phenotype-genotype correlation in antenatal and neonatal variants of Bartter syndrome. Nephrol Dial Transplant 2009;24:1455-1464.

-2 International Collaborative Study Group for Bartter-Like Syndromes: Mutations in the gene encoding the inwardly-rectifying renal potassium channel, ROMK, cause the antenatal variant of Bartter syndrome: evidence for genetic heterogeneity. Hum Molec Genet 1997;6:17-26.

-3 Ohlsson A, Sieck U, Cumming W, Akhtar M, Serenius F: A variant of Bartter's syndrome: Bartter's syndrome associated with hydramnios, prematurity, hypercalciuria and nephrocalcinosis. Acta Paediatr Scand 1984;73:868-874.

-4 Pereira PC, Miranda DM, Oliveira EA, Simões e Silva AC: Molecular pathophysiology of renal tubular acidosis. Curr Genomics 2009;10:51-59.

5 Witkop CJ Jr: Amelogenesis imperfecta, dentinogenesis imperfecta and dentin dysplasia revisited, problems in classification. J Oral Pathol 1989;17:547-553.

-6 Wright JT, Torain M, Long K, Seow K, Crawford P, Aldred MJ, Hart PS, Hart TC: Amelogenesis imperfecta: genotype-phenotype studies in 71 families. Cells Tissues Organs 2011;194:279-283.

-7 O'Sullivan J, Bitu CC, Daly SB, Urquhart JE, Barron MJ, Bhaskar SS, Martelli-Júnior H, dos Santos Neto PE, Mansilla MA, Murray JC, Coletta RD, Black GC, Dixon MJ: Whole-exome sequencing identifies FAM20A mutations as a cause of amelogenesis imperfecta and gingival hyperplasia syndrome. Am J Hum Genet 2011;88:616-620.

8 Cho SH, Seymen F, Lee KE, Lee SK, Kweon YS, Kim KJ, Jung SE, Song SJ, Yildrim M, Bayram M, Tuna EB, Gencay K, Kim JW: Novel FAM20A mutations in hypoplastic amelogenesis imperfecta. Hum Mutat 2012;33:91-94.

-9 Martelli-Júnior H, Santos Neto PE, Aquino SN, Santos CCO, Borges SP, Oliveira EA, Lopes MA, Coletta RD: Amelogenesis imperfecta and nephrocalcinosis syndrome: a case report and review of the literature. Nephron Physiol 2011;118:62-65.

-10 Martelli-Júnior H, Bonan PR, Dos Santos LA, Santos SM, Cavalcanti MG, Coletta RD: Case reports of a new syndrome associating gingival fibromatosis and dental abnormalities in a consanguineous family. J Periodontol 2008;79:1287-1296.

-11 Reis GS, Miranda DM, Pereira PCB, Sarubi HC, Rodrigues LB, De Marco LAC, Simões e Silva AC: Application of molecular biology at the approach of Bartter's syndrome: case report. J Bras Nefrol 2012;34:82-86. 
12 Bahadure RN, Thosar N, Kriplani R, Baliga S, Fulzele P: Dental aspect of distal tubular renal acidosis with genu valgum secondary to rickets: a case report. Case Rep Dent 2012;2012:374945.

13 Eastoe JE: Organic matrix of tooth enamel. Nature 1960;187:411-412.

-14 Thesleff I: Epithelial-mesenchymal signaling regulating tooth morphogenesis. J Cell Sci 2003;116: 1647-1677.

15 Coffield KD, Phillips C, Brady M, Roberts MW, Strauss RP, Wright JT: The psychosocial impact of developmental dental defects in people with hereditary amelogenesis imperfecta. J Am Dent Assoc 2005;136:620-630.

-16 Stechman MJ, Loh NY, Thakker RV: Genetic causes of hypercalciuric nephrolithiasis. Pediatr Nephrol 2009;24:2321-2332.

17 Hoppe B, Kemper MJ: Diagnostic examination of the child with urolithiasis or nephrocalcinosis. Pediatr Nephrol 2010;25:403-413.

-18 Sayer JA, Carr G, Simmons NL: Nephrocalcinosis: molecular insights into calcium precipitation within the kidney. Clin Sci 2004;106:549-561. 